\title{
Associative strength over time of first and second list responses in color context
}

\author{
JOSEPHINE M. RANDEL and CHARLES HAVRDA, \\ Department of Psychology, Sacred Heart University, \\ Bridgeport, Conn. 06604
}

Two aspects of the strength of first and second list associations in an $A-B, A-C$ paradigm were studied in a modified free recall test. First, this was tested over three time periods: $1 \mathrm{~min}, 4-5 \mathrm{~h}$, and $24 \mathrm{~h}$ after learning. Second, the use of the same color in the recall test as in either List 1 or List 2 was studied. It was found that in general, (1) List 2 responses are dominant when recall is immediate, but this advantage is lost after $24 h ;(2)$ when the recall test context is the same as that of List 1, the superiority of List 2 tends to be lost as early as $5 \mathrm{~h}$ after recall, but this effect is not statistically significant.

In our experience with verbal learning it is obvious that certain words which may be designated as stimuli get associated with, or connected to, more than one response. Which of these responses will be evoked at any specific time is the subject of this study.

Using the A-B, A-C retroactive inhibition paradigm, Briggs (1954) found that as learning progressed on a second set of responses to the same stimuli, the first set of responses were less frequently recalled. However, when recall was tested hours and days after learning had taken place, the responses from the first list increased to the same level as the second list responses. Using the same modified free recall test by which the $S$ is presented with the stimulus alone and asked to give a response, Barnes \& Underwood (1959) had the S recall both responses rather than any one to ensure obtaining all available responses, and again observed the superiority of the second list responses. A later study also confirmed this (Goggin, 1963). While the Barnes and Underwood study does support the theory of extinction of first responses as an explanation for retroactive inhibition, it did not carry its technique further than recall tests during the learning of the second list. The present study will attempt to give further evidence of the conditioning paradigm by calling for both responses over time and thereby demonstrating a spontaneous recovery of first list associations.

To further investigate the factors favoring the recall of first or second list responses, the role of background stimuli was considered. Second list responses may be given immediately after recall because of the continuity of background conditions which serve as cues for that particular response. Previous work has shown that retroactive inhibition decreases when background factors such as the testing room and apparatus are different during intervening learning, but the same during original learning and recall (Greenspoon \& Renyard, 1957). The same results were obtained when a different color-shape context was used for the intervening list than for the original list and its recall (Gottlieb \& Lindauer, 1967).

Here, in a modified free recall test, it was expected that first list associations would be recalled to a greater extent when the background color at recall is the same as that at original learning, while second list associations would dominate when the background at recall is the same as that for second list learning. In addition, the present study will attempt to assess the effect of a color context on the recall of first or second list responses over time.

\section{MATERIALS}

Three lists of eight paired associates each were used. One of these lists was a practice list and consisted of first and last names of psychologists, most of whom were unknown to the Ss. The first name served as the stimulus and the last as the response. For the two lists which were used in the experiment proper, the same eight nonsense syllables were used as stimuli. These CVCs had rated association values from 2.11 to 2.74 on a scale ranging from 1 to 5 (Noble, 1961). A separate set of responses was selected for each of the two lists. These were dissyllabic units, most of which were words, in the middle range of a scale (4.26 to 5.68) quantified by the average frequency of associations written in $60 \mathrm{sec}$ (Noble \& Parker, 1960). Half the Ss in each condition were given one of these lists first while the other half were given the other list first.

The lists were typed in capital letters on a green, pink, or white sheet of paper which gave the desired context. Three arrangements of each list were used to prevent serial learning. A standard Lafayette memory drum with manually operated shutters was set at a $2 \mathrm{sec}$ exposure rate, leaving an intertrial interval of $20 \mathrm{sec}$.

\section{SUBJECTS}

A total of 72 Ss was taken from introductory general and experimental psychology classes. None of the Ss had previous experience with paired-associate learning. 24 Ss were used in each of the three background color conditions, with a further division of each group into one of three time periods for recall.

\section{PROCEDURE}

When the Ss arrived for the experiment they were assigned to one of the three basic color conditions and one of the three time periods for recall. The three color conditions were: (1) $X Y X$, where the background color for learning List 1 and the recall task were the same-either green or pink-and the background color for the intervening List 2 was the other different color-either green or pink; (2) XYY, where the background color for the recall task was the same as that for List 2, but different from List 1 ; and (3) the control condition, where each list was presented against the usual white background.

Before List 1 was presented, a warm-up task was given whereby the Ss were instructed in the paired-associate procedure and required to learn the set of eight paired names to the criterion of one perfect recitation. Then, after $1 \mathrm{~min}$, List 1 was learned to the same criterion followed by another 1 -min interval and the learning of List 2 to the same criterion. The $\mathrm{S}$ was then given the diversionary task of tracing a star for $1 \mathrm{~min}$ while looking in a mirror rather than at his hand.

The recall test was given at one of three intervals after the mirror drawing task for each background condition, giving a further breakdown of eight $S$ s in each interval for each context. These time intervals were (1) immediate, (2) 4 or $5 \mathrm{~h}$ later, or (3) $24 \mathrm{~h}$ later. For the recall task, the stimulus items were presented on the appropriate color background for the particular condition and the $S$ was asked to vocally recall both of the responses which he had learned to the stimulus. He was allowed $15 \mathrm{sec}$ for each stimulus.

\section{RESULTS}

For the practice list, the mean number of trials to criterion of each group of eight Ss ranged from 10.25 to 13.75 , these groups not differing significantly.

The mean number of responses recalled in each list for each 
Table 1

Mean Number of Responses Recalled from Each List Under Three Contexts After Three Time Intervals

\begin{tabular}{lccc}
\hline Lists & XYX & $\begin{array}{c}\text { Conditions } \\
\text { XYY }\end{array}$ & Control \\
\hline 1 & Immediate Recall & \\
\hline 2 & 3.87 & 4.30 & 4.50 \\
& 6.12 & 4.75 & 5.12 \\
\hline 1 & & $4-5$ h later & 3.62 \\
2 & 4.37 & 3.12 & 4.62 \\
\hline & 3.50 & 4.00 & \\
\hline 1 & & 24 h later & 4.37 \\
2 & 4.75 & 5.00 & 3.25 \\
\hline
\end{tabular}

of the time periods is presented in Table 1. For condition XYY (where List 2 and the recall test have the same color backgrounds) and the control condition (white background), recall of List 2 is better at immediate recall and $5 \mathrm{~h}$ later, but this is reversed after $24 \mathrm{~h}$ in favor of List 1. This agrees with Briggs' (1954) data for recall over time. For condition XYX (same background color for List 1 and the recall test), recall of List 2 is better immediately but this advantage is overcome by List 1 as early as $5 \mathrm{~h}$ after learning. A three-way analysis of variance with repeated measures on the time factor (Winer, 1962) revealed only a significant interaction between time and list. Testing for simple effects of differences between lists at the three time intervals revealed a significant difference in favor of List 2 for immediate recall with no significant difference between the two lists on subsequent time periods. This is basically the result obtained by Briggs (1954) including the crossover in favor of List 1 between 5 and $24 \mathrm{~h}$, although in both studies the only significant difference between the two lists at any time period was found to occur immediately.

Although no significant differences were found among the three color context conditions, it is interesting to note that for the XYX condition, List 1 has an advantage over List 2 starting with the 5-h time period.

A further analysis was performed to determine the number of times both responses were given to a stimulus as opposed to the number of single responses given. This was found to be 4.28 vs 4.38 , respectively. Thus, it appears that if one response is recalled to a particular stimulus, the other is just as likely to be recalled as not, minimizing the effect of any conflicting tendency.

\section{DISCUSSION}

An important question to be answered here is the reason for the lack of a significant effect of the background color conditions. In retrospect, the fact that no differential response was required to the various backgrounds, which has been found to be necessary for incidental learning (Deese \& Hulse, 1967), may be important. Where an effect was found in a previous study (Gottlieb \& Lindauer, 1967), attention was called to the background stimuli, while here it was not. Some influence may have been exerted as evidenced by the different points of crossover for Lists 1 and 2 for the $X Y X$ and $X Y Y$ groups, indicating an earlier effect of the color influence in time when List $I$ and the recall test have the same context. When other contextual stimuli have been found to have an effect, more than one stimulus characteristic was involved in the background, either in the form of the room and apparatus (Greenspoon \& Renyard, 1957) or in the use of both color and a background shape (Gottlieb \& Lindauer, 1967). Apparently color itself does not have a strong effect.

Since it has been shown that when both responses are called for over time the same results are obtained as with one required response, further evidence is gathered for a conditioning explanation of retroactive inhibition in the A-B, A-C paradigm. The recovery of List 1 responses over time is in keeping with the spontaneous recovery aspect of conditioning. In addition, Miller \& Dollard's (1941) concept of response hierarchy could be used to explain what happens when two responses are learned to the same stimulus. The second response is temporarily stronger, but rather than an unlearning of the first response, it has dropped to a second place in the response hierarchy. With the passage of time, the response hierarchy may shift or the relative difference between first and second place may be minimal, making either response as likely to occur.

\section{REFERENCES}

BARNES, JEAN M., \& UNDERWOOD, B. J. "Fate" of first-list associations in transfer theory. Journal of Experimental Psychology, $1959,58,97-105$.

BRIGGS, G. E. Acquisition, extinction, and recovery functions in retroactive inhibition. Journal of Experimental Psychology, 1954, 47, $285-293$.

DEESE, J., \& HULSE, S. H. The psychology of learning. (3rd ed.) New York: McGraw-Hill, 1967.

GOGGIN, JUDITH. Influence of the written recall measure on first-list associations. Journal of Experimental Psychology, 1963, 65, 619-620.

GOTTLIEB, WILMA, \& LINDAUER, M. S. The effect of contextual stimuli on retroactive inhibition. Psychonomic Science, 1967, 9, 331-332.

GREENSPOON, J., \& RENYARD, R. Stimulus conditions and retroactive inhibition. Journal of Experimental Psychology, 1957, 53, 55-59.

MILLER, N. E., \& DOLLARD, J. Social learning and imitation. New Haven, Conn.: Yale University Press, 1941.

NOBLE, C. E. Measurements of association value (a), rated associations $\left(a^{\prime}\right)$, and scaled meaningfulness $\left(\mathrm{m}^{\prime}\right)$ for the $2100 \mathrm{CVC}$ combinations of the English alphabet. Psychological Reports, 1961, 8, 487-521.

NOBLE, C. E., \& PARKER, G. V. C. The Montana scale of meaningfulness. Psychological Reports, 1960, 7, 325-331.

WINER, B. J. Statistical principles in experimental design. New York: McGraw-Hill, 1962. 